\title{
VALORES DE REFERÊNCIA DA CONCENTRAÇÃO DE METAIS PESADOS EM SOLOS NA AMAZÔNIA CENTRAL
}

\author{
Ananda Gabrielle de Matos Rebêlo ${ }^{\mathrm{a}, *,(}$, Maria Terezinha Ferreira Monteiroa , Sávio José Filgueiras Ferreira ${ }^{\mathrm{a}}$, Eduardo \\ Antonio Ríos-Villamizara, Carlos Alberto Nobre Quesada ${ }^{\mathrm{b}}$ e Sergio Duvoisin Junior ${ }^{\mathrm{c}}$ \\ ${ }^{a}$ Departamento de Hidrobiogeoquímica, Instituto Nacional de Pesquisas da Amazônia, 69067-375 Manaus - AM, Brasil \\ ${ }^{b}$ Departamento Biogeoquímica, Instituto Nacional de Pesquisas da Amazônia, 69067-375 Manaus - AM, Brasil \\ 'Departamento de Química, Universidade do Estado do Amazonas, 69020-070 Manaus - AM, Brasil
}

Recebido em 02/10/2019; aceito em 06/02/2020; publicado na web em 13/04/2020

\begin{abstract}
REFERENCE VALUES OF THE HEAVY METALS NATURAL CONCENTRATIONS IN SOILS OF THE CENTRAL AMAZON. Considering the size of the Amazon region and the need for studies to establish soil trace metal concentrations in natural environments, the objective of this work was to evaluate heavy metal contents in a toposequence of an Amazon State microbasin. Soil samples were collected in three native forest topographic positions. Samples were opened for analysis by two methods: exchangeable cations were determined by the silver thiourea method and total metal elements by sulfuric acid. The metals were determined by atomic absorption spectrometry. In general, it was observed low concentration of several elements considered essential to plant growth in the studied soils, indicating low concentration in the source material of these soils and the intense weathering leaching. The higher concentrations of heavy metals found in the Plateau / Shed areas may be related to clay soils and more acidic pH than other topographies. Exchangeable Al was found at higher concentrations, while Na was the element with the lowest concentration. Total metallic elements presented higher availability potential in the Plateau / Shed areas, except for B, Cr, Mo and Ni. These differences justify the development of regionalized studies for heavy metals in soils appropriate to the conditions of each environment.
\end{abstract}

Keywords: metallic elements; tropical ecosystems; natural contents; values oriented.

\section{INTRODUÇÃO}

Metais-traço são elementos químicos com densidade superior a $5 \mathrm{mg} \mathrm{cm}^{-3}$ e número atômico maior que 20 , estáveis e não degradáveis. A concentração desses elementos no solo encontra-se naturalmente devido a ação do intemperismo da rocha mãe e de outros processos pedogenéticos no material de origem do solo. Esses metais participam do arranjo cristalino de diferentes minerais, fundamentado pelo seu papel geoquímico e sua divisão durante a cristalização dos elementos mineralógicos da rocha. ${ }^{1}$

A concentração natural desses elementos na crosta terrestre é comumente referida pelos geoquímicos como nível de background, e para alguns elementos, este valor, ou faixa de valores é função da natureza do material. ${ }^{2}$ Portanto, para se avaliar áreas potencialmente contaminadas, o conhecimento da concentração e variabilidade em ambiente naturais é essencial. Todavia, existe uma grande dificuldade na obtenção desses dados, devido aos impactos negativos de atividades humanas em graus diferenciados em escala global. No entanto, em áreas naturais, as concentrações referem-se a locais onde o impacto antropogênico é mínimo ou inexistente. ${ }^{1}$

$\mathrm{O}$ conhecimento de teores naturais permite determinar valores padrão de qualidade do solo, além de avaliar o potencial de suprimento de nutrientes. Para a avaliação dos teores desses elementos em solos de referência da Amazônia central, é necessário a utilização de classes de solo representativas, em locais com ausência mínima de atividade antrópica e características de classificação conhecidas. ${ }^{3}$

Acredita-se que metais-traço são passíveis de acumulação especialmente no sistema solo, o qual, devido às suas características, pode tornar-se fonte de disponibilização para outros sistemas ambientais. Portanto, valores de referência de qualidade para solos, devem refletir a concentração natural de determinada substância

\footnotetext{
*e-mail: agmrebelo@gmail.com
}

no solo e, desse modo, fornecer a base para a avaliação da sua qualidade. $^{4}$

Em função das peculiaridades dos solos da Amazônia central, e assumindo a falta de valores de referência para os estados que abrangem essa região, é necessário estudos que possibilitem estabelecer valores orientadores da qualidade do solo, pois atualmente os valores já estabelecidos pelo Conselho Nacional do Meio Ambiente (Conama), pela Resolução n 420 de 29 de dezembro de 2009, não se aplicam e não podem ser generalizados para a tomada de decisão quanto a presença de substâncias tóxicas no solo ocasionadas por perturbações antrópica. Portanto, há uma urgência de estudos que possibilitem dispor de valores de referência para áreas naturais e que possam ser utilizados como valores de referência para essa vasta região. Isso enfatiza a importância do conhecimento dos teores naturais de elementos-traço em diferentes solos amazônicos, para evitar que níveis irrealistas de remediação sejam impostos em áreas contaminadas. $^{5}$

Deste modo, trabalhos que assegurem a qualidade ambiental do solo e, consequentemente, a proteção à população são necessários. Neste contexto, o objetivo do presente trabalho foi avaliar teores de metais pesados em diferentes perfis topográficos (platô/vertente, campinarana e baixio) de solo de uma microbacia do Estado do Amazonas, provenientes de ambientes naturais não antropizados visando caracterizar a ocorrência de teores desses metais.

\section{MATERIAIS E MÉTODOS}

\section{Área de estudo}

O estudo foi realizado na área de pesquisa da Reserva Biológica do Cuieiras do Programa de Grande Escala da Biosfera-Atmosfera na Amazônia (LBA) do Instituto Nacional de Pesquisas da Amazônia (INPA), localizada a $60 \mathrm{~km}$ ao norte da cidade de Manaus. Esta reserva 
tem acesso apenas pela estrada vicinal ZF-2, com entrada pelo $\mathrm{km} 50$ da BR-174, percorrendo $34 \mathrm{~km}$ de ramal de estrada de barro até ao alojamento do LBA/INPA, e fica localizada em uma área de floresta primaria medindo cerca de 22.735 ha.

\section{Caracterização fisiográfica}

O relevo é caracterizado por áreas de platô, vertente, campinarana e baixio que apresentam flora diferenciada. Nos platôs, localizados nas áreas mais elevadas, a floresta tem maior biomassa, caracterizando-se por vegetação com dossel entre 35-40 metros, com muitas árvores emergentes com altura superior a $45 \mathrm{~m}$. A floresta das vertentes, caracterizadas por elevada declividade, apresenta dossel de 25 a $30 \mathrm{~m}$, com menos árvores emergentes. As áreas de campinarana apresentam baixa produtividade, baixa diversidade e solo com elevado oligotrofismo e acidez, quando comparados às florestas de terra firme. Já as de baixio, caracterizam-se pela presença de poucas árvores emergentes, com sub-bosque denso formado por plantas com muitas raízes superficiais e árvores que sofrem influências de cursos de água, com raízes escoras adventícias. Seu dossel varia entre 20 e $35 \mathrm{~m} .{ }^{6,7}$

O clima na Amazônia central, pela classificação de Köppen, é do tipo "Am", conceituado como megatérmico (tropical úmido). A precipitação anual varia de 1.800 a $2.800 \mathrm{~mm}$, com uma estação chuvosa de dezembro a maio, ultrapassando $300 \mathrm{~mm}$ mensal nos meses de março a abril. ${ }^{8} \mathrm{~A}$ média anual de temperatura é de $26{ }^{\circ} \mathrm{C}$ com temperatura média do mês mais frio acima de $18^{\circ} \mathrm{C}$. A variação térmica diurna é bem maior do que a anual, com temperatura média mínima e máxima entre $23,5^{\circ} \mathrm{C}$ e $31,2^{\circ} \mathrm{C}$, respectivamente. Em valores médios mensais a temperatura varia de um mínimo de $24,5{ }^{\circ} \mathrm{C}$ na estação chuvosa, para pouco mais de $27^{\circ} \mathrm{C}$ na estação seca. ${ }^{9}$

\section{Amostras de solo}

As amostras de solo foram obtidas de pesquisas realizadas por Quesada et al..$^{10}$ para o ano 2003. Dentro de cada área amostrada, para cada profundidade $(0-0,05 ; 0,05-0,1 ; 0,1-0,2 ; 0,2-0,3 \mathrm{~m})$ foram coletadas cinco amostras utilizando um amostrador de solo não perturbado. Todas as amostras foram secas ao ar. Retirou-se das amostras raízes, detritos, pequenas pedras e partículas maiores que $2 \mathrm{~mm}$ e depois foram peneiradas com malhas a $2 \mathrm{~mm}$.

\section{Determinação química do solo}

As amostras de solo foram analisadas no Laboratório Temático de Solo e Planta do Instituto Nacional de Pesquisas da Amazônia (INPA), Manaus, Brasil. O pH do solo foi determinado com 1:2,5 de $\mathrm{H}_{2} \mathrm{O}$ extraído com $10 \mathrm{~g}$ de terra fina agitada com $25 \mathrm{~mL}$ de $\mathrm{H}_{2} \mathrm{O}$ por 1 hora em um agitador circular. As concentrações totais de $\mathrm{C}$ e $\mathrm{N}$ foram feitas pelo analisador Vario Max CN (Elementar, Alemanha), em solo seco em estufa a $65^{\circ} \mathrm{C}$ por $72 \mathrm{~h}$ e após moagem a fino pó.

Os cátions trocáveis $(\mathrm{Ca}, \mathrm{Mg}, \mathrm{K}, \mathrm{Na}$ e $\mathrm{Al})$ foram determinados pelo método da Tioureia e Nitrato de Prata (Ag-TU). Este é um método rápido e conveniente que permite uma extração centrífuga de uma etapa com solução $0,01 \mathrm{M}$ Ag-TU através da qual a troca completa de cátions é alcançada. Outras vantagens deste método incluem a baixa molaridade do extrator, sua alta efetividade em uma ampla gama de valores de $\mathrm{pH}$ do solo, e uma excelente comparação com outros métodos como $\mathrm{NH}_{4} \mathrm{Ac}$ e $1 \mathrm{M} \mathrm{KCl} .^{11}$

Para a extração dos cátions trocáveis, amostras de $5 \mathrm{~g}$ de solo (seco ao ar, passado por uma peneira de $2 \mathrm{~mm}$ ), foram transferidas para um tubo de centrífuga de polietileno de $50 \mathrm{~mL}$, no qual adicionou-se $40 \mathrm{~mL}$ de Ag-TU 0,01 M e agitou-se durante quatro horas numa máquina de agitação recíproca. Em seguida, separou-se o sobrenadante transparente do solo por centrifugadora (velocidade de $3000 \mathrm{rpm}$ ou mais por $15 \mathrm{~min}$ ) e em seguida filtrou-se através de filtros Whatman 43.

Para a concentração total de elementos, as amostras de solo foram extraídas por digestão ácida com ácido sulfúrico $\left(\mathrm{H}_{2} \mathrm{SO}_{4}\right)$ concentrado seguido de peróxido de hidrogênio $\left(\mathrm{H}_{2} \mathrm{O}_{2}\right)$. Pesou-se aproximadamente $5 \mathrm{~g}$ de solo e adicionaram-se $5,0 \mathrm{~mL}$ de ácido sulfúrico concentrado em um balão de digestão Hach de 100 mL. Para a digestão das amostras utilizou-se o aparelho Digesdahl® Hach. Após o início da ebulição do ácido sulfúrico deixou-se o sistema em aquecimento por 10 min e adicionou-se $10,0 \mathrm{~mL} \mathrm{de} \mathrm{H}_{2} \mathrm{O}_{2}$, aquecendo o sistema por mais 5 min. Em seguida, removeu-se o balão do aquecedor, deixou-se o conteúdo resfriar à temperatura ambiente e completou-se o volume para $100 \mathrm{~mL}$ em um balão volumétrico previamente calibrado.

A decomposição por esse método apresenta uma grande utilidade na determinação de baixas concentrações de metais em vários tipos de amostras, porque muitos elementos de interesse são convertidos em cátions inorgânicos simples não voláteis, que permanecem no meio ácido.

O controle de qualidade da análise foi realizado utilizando extratos da referência padrão SRM 2710 do solo de Montana (Instituto Nacional de Padrões de Tecnologia, Gaithersburg, MD, EUA). Para análise, foram realizadas amostras compostas do solo de cada topografia tanto para os cátions trocáveis quanto para os elementos totais. A verificação dos metais foi realizada utilizado dois brancos, preparados a partir de cada solução utilizada para a digestão. Soluções padrão dos metais foram preparadas por diluição a partir de solução padrão estoque de concentração $1.000 \mathrm{mg} \mathrm{L}^{-1}$, para elaboração das curvas analíticas.

A análise dos elementos químicos no extrato foi obtida por espectrometria de absorção atômica em chama de ar/acetileno (FAAS). Este método apresenta limitações na precisão e limites de detecção demasiado altos para gamas $\mu \mathrm{g} \mathrm{L}^{-1}$, ou seja, gamas mais baixas. Portanto, diluições de amostras de $\mathrm{Ca}, \mathrm{Mg}$ e $\mathrm{Al}$ foram feitas usando uma solução de $0,55 \%$ de supressor de lantânio.

\section{Análise dos resultados}

O agrupamento espacial do total das concentrações dos metais traço no solo foi realizado pela técnica de Análise de Componentes Principais (ACP), com o software Past ${ }^{\circledR}$ para análises estatísticas, analisando as covariâncias e as correlações. A análise de agrupamento é um conjunto de técnicas estatísticas que identificam subgrupos ou classes distintas de metais no solo com base nas similaridades ou dissimilaridades existentes, ou seja, os mais semelhantes pertencem ao mesmo grupo e as amostras ou locais que são heterogêneos entre si, pertencem a grupos distintos. ${ }^{12}$

\section{RESULTADOS}

As amostras coletadas nos três diferentes tipos topográficos, apresentaram características típicas de solos extremamente a fortemente ácidos, com pH variando entre 3,94 e 4,73 (Tabela 1). Em geral, para a reação $\mathrm{C} / \mathrm{N}$ não houve grande variação para as três diferentes topografias estudadas. A não diferença entre os estoques da relação $\mathrm{C} / \mathrm{N}$ nas topografias pode ser resultado da menor quantidade de amostras coletadas e da variabilidade natural dos solos. A razão $\mathrm{C} / \mathrm{N}$ é considerada um indicativo do grau de humificação da matéria orgânica presente em solos e sedimentos.

Observou-se que mais de $60 \%$ da argila está concentrada nas áreas de Platô/Vertente, seguido respectivamente pelo Baixio e Campinarana. O inverso acontece com a fração de areia, cujas maiores concentrações estão nas áreas de Campinarana e Baixio, 
respectivamente. Em função dos atributos físicos e químicos do solo, classificaram-se os solos como Latossolo para o ambiente mais argiloso e Espodossolo para ambientes arenosos.

Tabela 1. Atributos físicos e químicos do solo nos diferentes tipos topográficos em ambiente de floresta natural na Amazônia central

\begin{tabular}{lcccccc}
\hline \multirow{2}{*}{ Área } & $\mathrm{pH}$ & $\mathrm{C} / \mathrm{N}$ & Areia & Argila & Silte & \multirow{2}{*}{$\begin{array}{c}\text { Tipo de } \\
\text { solo }\end{array}$} \\
\cline { 5 - 6 } & & & & $(\%)$ & & Platô/Vertente \\
\cline { 5 - 6 } & 3,94 & 17,21 & 19,90 & 67,71 & 12,39 & Latossolo \\
Campinarana & 4,10 & 15,94 & 96,00 & 2,00 & 2,00 & Espodossolo \\
Baixio & 4,73 & 17,63 & 89,00 & 9,00 & 2,00 & Espodossolo \\
\hline
\end{tabular}

Os baixos valores de $\mathrm{pH}$ neste estudo, correspondentes a ambientes de solos ácidos, são comuns nas regiões sob condições tropicais onde a grandeza da precipitação pluviométrica é tal que os elementos alcalinos, notadamente o $\mathrm{Ca}^{2+}$ e o $\mathrm{Mg}^{2+}$, são lixiviados das camadas superiores pelas águas contendo $\mathrm{CO}_{2}$, sendo substituídos nos coloides pelos íons $\mathrm{H}^{+} \cdot{ }^{13}$ Essas condições, de modo geral, favorecem a solubilização e mobilização de metais pesados na solução do solo e, por extensão, as perdas desses elementos por lixiviação. Resultados de $\mathrm{pH}$ em água deste estudo foram semelhantes aos encontrados por Campos et al. ${ }^{14}$ que estudou solos não antropogênicos na região de Manicoré - AM.

A Tabela 2 apresenta os teores disponíveis dos elementos cálcio $(\mathrm{Ca})$, magnésio $(\mathrm{Mg})$, potássio $(\mathrm{K})$, sódio $(\mathrm{Na})$ e alumínio $(\mathrm{Al})$ nos diferentes compartimentos topográficos do solo. As concentrações dos elementos químicos trocáveis ou assimiláveis para as áreas estudadas seguiram, em geral, a seguinte ordem: $\mathrm{Al}>\mathrm{Ca}>\mathrm{Mg}>\mathrm{K}>\mathrm{Na}$. De forma geral, todos os elementos foram encontrados em baixa quantidade, em virtude da baixa concentração no material de origem destes solos e da lixiviação pelo intenso intemperismo.

Observou-se então, altos valores de Al trocável neste estudo principalmente para as áreas de Platô/Vertente. Porém, em solos arenosos, como é o caso do Baixio encontrou-se valor baixo, aproximadamente 17 vezes menor do que nos ambientes argilosos. Os elevados valores do $\mathrm{Al}$ trocável já eram esperados, visto que o $\mathrm{Al}$ é o metal mais abundante no solo, uma vez que a maior parte dos minerais primários e secundários das rochas formados pela ação do intemperismo são alumino silicatos, que, quando decompostos pela água carregada de gás carbônico, liberam o alumínio na forma trocável $\left(\mathrm{Al}^{3+}\right) .{ }^{15}$ Os valores encontrados neste estudo foram similares ao estudo de Barroco Neta e Nishiwaki, ${ }^{9}$ com valores de 20,0 mmol $_{\mathrm{c}} \mathrm{kg}^{-1}$ para platô e 5,0 $\mathrm{mmol}_{\mathrm{c}} \mathrm{kg}^{-1}$ para o baixio.

Os valores de cálcio e magnésio trocáveis apresentaram padrões idênticos de distribuição espacial, com teores mais altos nas áreas de platô/vertente, verificando assim o aumento das concentrações desses elementos em locais com acúmulo de matéria orgânica em função da maior biomassa aérea. Os valores de $\mathrm{Ca}$ e $\mathrm{Mg}$ para as áreas de platô foram semelhantes aos encontrados por Zaninetti et al., ${ }^{16}$ que observaram valores de 1,0 mmol $_{\mathrm{c}} \mathrm{kg}^{-1}$ para $\mathrm{Ca}$ e $1,7 \mathrm{mmol}_{\mathrm{c}} \mathrm{kg}^{-1}$ para $\mathrm{Mg}$ em Latossolo de uma floresta natural na região Amazônica. Barroco Neta e Nishiwaki ${ }^{9}$ também verificaram valores semelhantes ao deste estudo, com 0,7 a 1,3 $\mathrm{mmol}_{\mathrm{c}} \mathrm{kg}^{-1}$ no Platô e 0,4 a $0,8 \mathrm{mmol}_{\mathrm{c}} \mathrm{kg}^{-1}$ na vertente e no baixio, respectivamente.

O potássio foi o elemento de concentração intermediária encontrada no solo, com maiores valores no ambiente topográfico de campinarana, seguido de platô/vertente e baixio. Os valores de potássio, abaixo daqueles correspondentes ao $\mathrm{Ca}$ e $\mathrm{Mg}$, podem ser explicados pela sua facilidade em ser lixiviado, uma vez que o elemento não faz parte de nenhum componente estrutural dos tecidos orgânicos, além disso a passagem do $\mathrm{K}$ solúvel para a forma não trocável é rápida e
Tabela 2. Concentrações disponíveis dos principais elementos encontrados no solo em três diferentes topografias em ambiente de floresta natural na Amazônia central

\begin{tabular}{lccccc}
\hline & \multicolumn{5}{c}{ Elementos Disponíveis $\left(\mathrm{mmol}_{\mathrm{c}} \mathrm{kg}^{-1}\right)$} \\
\cline { 2 - 6 } & $\mathrm{Ca}$ & $\mathrm{Mg}$ & $\mathrm{K}$ & $\mathrm{Na}$ & $\mathrm{Al}$ \\
\hline Platô/Vertente & 1,10 & 1,00 & 0,90 & 0,60 & 18,20 \\
Campinarana & 0,60 & 1,00 & 1,10 & 0,50 & 17,00 \\
Baixio & 0,30 & 0,50 & 0,40 & 0,10 & 1,80 \\
\hline
\end{tabular}

eficiente, garantindo que parte desse íon permaneça no solo como forma não disponível. ${ }^{17}$ Barroco Neta e Nishiwaki ${ }^{9}$ encontraram valores iguais para as áreas de Platô $\left(0,9 \mathrm{mmol}_{\mathrm{c}} \mathrm{kg}^{-1}\right)$ e semelhantes para o baixio $\left(0,5 \mathrm{mmol}_{\mathrm{c}} \mathrm{kg}^{-1}\right)$.

Já o sódio trocável foi o elemento de menor concentração para os três diferentes tipos topográficos, tendo valores mais elevados na área de Platô/Vertente (Tabela 2). As menores concentrações de sódio encontradas neste estudo, podem ser explicadas pelo fato deste elemento não ser muito utilizado pelas plantas, logo apresenta uma baixa quantidade no solo, além disso, o aumento deste elemento, pode tornar o solo adensado, compacto em condições secas, disperso e pegajoso em condições molhadas. ${ }^{18}$ Pedrotti et al. ${ }^{19}$ indicam que o sódio aumenta consideravelmente a extensão das frações de argila, ocasionando a dispersão das mesmas, dificultando o movimento de ar e de água no solo e formando camadas impermeáveis.

Para os elementos metálicos totais $(\mathrm{B}, \mathrm{Ba}, \mathrm{Co}, \mathrm{Cr}, \mathrm{Cu}, \mathrm{Fe}, \mathrm{Mn}$, $\mathrm{Mo}, \mathrm{Ni}, \mathrm{Si}, \mathrm{Sr}, \mathrm{Ti}, \mathrm{V}$ e Zn) foi obtido um número relativamente alto de variáveis, portanto o emprego de técnicas exploratórias, como é o caso da Análise dos Componentes Principais (ACP), permitiu reduzir uma grande quantidade da informação fornecida pelo conjunto das variáveis originais. A Figura 1 e Tabela 3 ilustra as similaridades entre as variáveis (Loadings) e a similaridade entre as amostras (Scores).

Pode-se observar que o modelo para a ACP foi obtido com 2 CPs, onde os componentes principais 1 e 2, explicaram $89 \%$ e $11 \%$ da variabilidade total dos dados, respectivamente. Os loadings do componente principal 1, que é o arranjo que melhor representa a distribuição dos dados, correlacionaram-se positivamente com a maioria dos metais, exceto para Mo $(-0,28)$, Ni $(-0,27), \mathrm{Cr}(-0,26)$ e B $(-0,11)$, enquanto que para o componente principal 2 , todos tiveram correlação positiva, no entanto, alguns metais se destacaram, como é o caso do B $(0,74), \mathrm{Cu}(0,46), \mathrm{Cr}(0,34)$ e $\mathrm{Zn}(0,22)$.

$\mathrm{A}$ análise por componentes principais evidenciou que: 1) na área Platô/Vertente (P/V) prevaleceram os metais Ba, Co, Fe, Mn, Si, Sr, $\mathrm{Ti}, \mathrm{V}, \mathrm{Zn}$ e $\mathrm{Cu}$, indicando uma maior concentração destes com solos mais argilosos e maior acúmulo de matéria orgânica; 2) na área do Baixio (B) a predominância foi dos metais $\mathrm{Mo}, \mathrm{Ni}, \mathrm{Cr}$ e B; e 3) na área de Campinarana não houve representatividade de nenhum dos elementos.

De forma geral, as maiores concentrações dos elementos metálicos totais encontrados em solos argilosos (Platô/Vertente), podem ser explicadas pelos atributos físicos e químicos do solo que contribuem decisivamente para o comportamento apresentado por um solo sem atividade antrópica. Com relação aos metais pesados, é de se esperar que um solo mais argiloso apresente em seu complexo sortivo uma quantidade maior destes elementos, se levarmos em consideração apenas esta característica. Outro atributo que influencia este processo é o pH do solo, o qual contribui para a formação de cátions metálicos, quando há uma diminuição de seus valores.

Apesar do boro ser escasso em solos arenosos, uma vez que este é facilmente lixiviado, ele foi o elemento mais encontrado no Baixio com 54,68 $\mathrm{mg} \mathrm{kg}^{-1}$ (solos arenosos). Biondi et al., ${ }^{3}$ analisando bário em solos de referência do estado de Pernambuco, encontram valores 


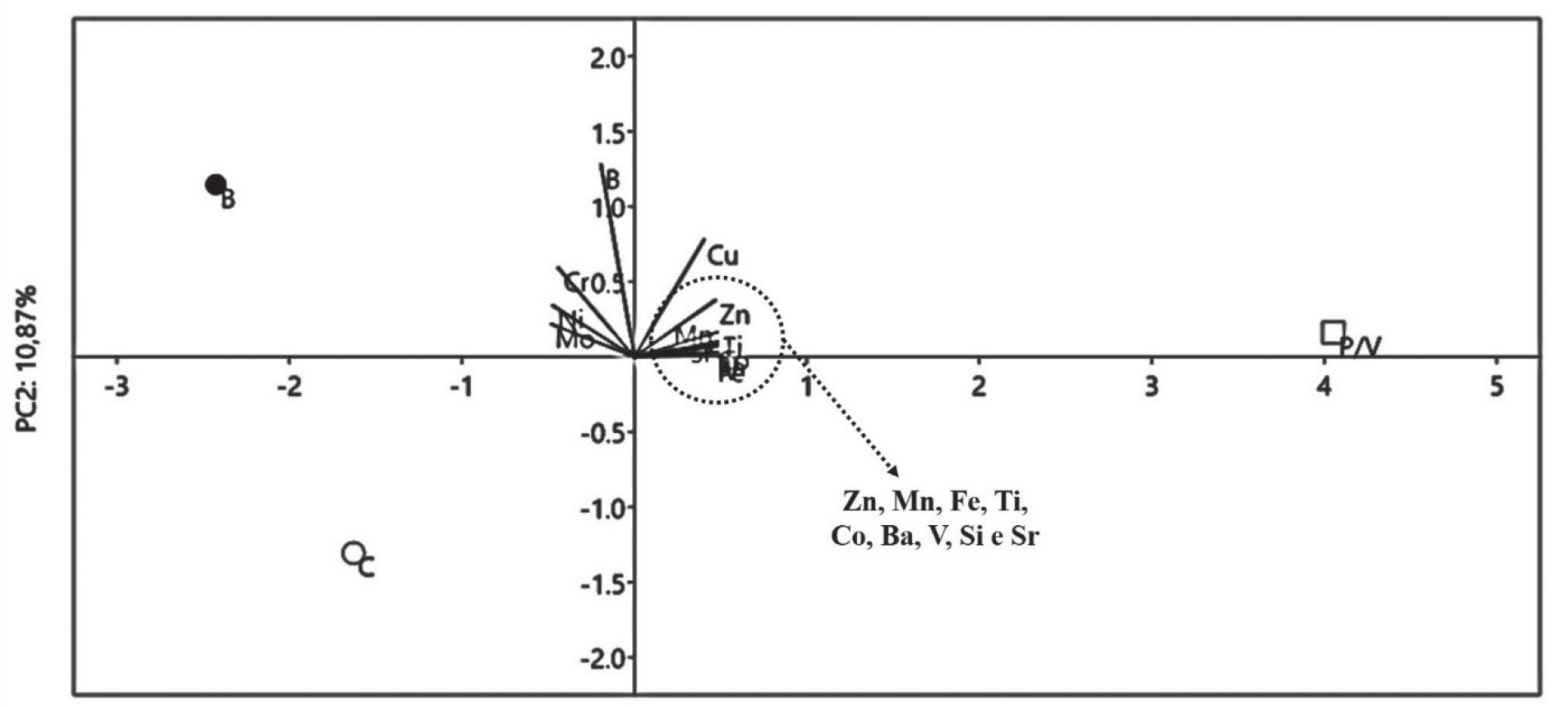

\section{PC1: $89,12 \%$}

Figura 1. ACP: gráfico de loadings e scores correspondentes às três áreas topográficas para os 14 metais traço (Platô/Vertente: P/V; Campinarana: $C$; Baixio: B)

Tabela 3. Contribuição entre cada componente principal e variáveis analisadas (metais)

\begin{tabular}{lll}
\hline & ACP1 & ACP2 \\
\hline Boro (B) & $-0,112$ & 0,744 \\
Bário (Ba) & 0,283 & 0,004 \\
Cobalto (Co) & 0,282 & 0,061 \\
Crômio (Cr) & $-0,256$ & 0,344 \\
Cobre (Cu) & 0,235 & 0,456 \\
Ferro (Fe) & 0,283 & 0,017 \\
Manganês (Mn) & 0,281 & 0,095 \\
Molibdênio (Mo) & $-0,279$ & 0,127 \\
Níquel (Ni) & $-0,274$ & 0,198 \\
Silício (Si) & 0,282 & 0,058 \\
Estrôncio (Sr) & 0,283 & 0,019 \\
Titânio (Ti) & 0,283 & 0,049 \\
Vanádio (V) & 0,283 & 0,002 \\
Zinco (Zn) & 0,273 & 0,219 \\
\hline
\end{tabular}

ACP1: Análise do Componente Principal 1; ACP2: Análise do Componente Principal 2.

variando entre 5,38 e 446,03 $\mathrm{mg} \mathrm{kg}^{-1}$. Tais valores são bem superiores aos encontrados nos solos deste estudo, no qual foi encontrada uma variação de 1,49 a $10,98 \mathrm{mg} \mathrm{kg}^{-1}$.

Para o cromo, existe uma grande variação na concentração entre as topografias estudadas. As maiores concentrações desse metal no Baixio podem indicar que ele é fortemente influenciado pela lixiviação. Sugere-se então, que as formas do relevo influenciam diretamente no comportamento do $\mathrm{Cr}$, em que a água oriunda da precipitação carrega esse metal do Platô, passa pela Campinarana e se concentra no Baixio.

Os teores de $\mathrm{Co}, \mathrm{Cu}$ e Ni nos solos foram considerados baixos em comparação a amplitude desses valores para solos de outras regiões do país. Por exemplo, Campos et al..$^{20}$ analisando 19 Latossolos de diferentes regiões do país e desenvolvidos a partir de vários materiais de origem, observaram teores de $\mathrm{Cu}$ variando entre 3 e $238 \mathrm{mg} \mathrm{kg}^{-1}$, e Ni variando entre 3 e $45 \mathrm{mg} \mathrm{kg}^{-1}$. Em um estudo realizado em solos de referência do estado do Pernambuco, Biondi et al. ${ }^{21}$ encontrou valores de $10,55 \mathrm{mg} \mathrm{kg}^{-1}$ para o $\mathrm{Ni}$ e de $7,43 \mathrm{mg} \mathrm{kg}^{-1}$ para o Co, sendo cada vez mais notável as diferenças encontradas nos valores desses elementos, de um estado para outro.

De modo geral, o Fe apresentou altas concentrações em relação aos demais elementos, sendo mais abundante na área de Platô/ Vertente com 20.372,55 mg kg-1 . A menor concentração apresentada no baixio pode ser explicada pela composição de solos arenosos, que têm como principal mineral o quartzo, e apresentam naturalmente pequenas quantidades de minerais que contém Fe em sua composição. ${ }^{22}$

A relação do $\mathrm{pH}$ com as quantidades de Fe e Mn também pode ser um fator a ser considerado, visto que quanto menor o $\mathrm{pH}$ de um solo, como é observado nas áreas de platô $(\mathrm{pH}<4)$, maiores as quantidades de Fe e Mn disponíveis para a planta, isso ocorre devido a formação de óxidos de ferro e manganês pouco solúveis. ${ }^{23}$

$\mathrm{O}$ Si, Sr, Ti e V totais apresentaram tendência de decrescimento partindo das áreas de platô/vertente, passando pela campinarana, até o baixio, indicando maior teor desses elementos em Latossolos. Os altos valores nas áreas de Platô/Vertente, podem estar associados ao tipo de solo que possui uma grande quantidade de silte e argila, além de um menor $\mathrm{pH}$, favorecendo na pouca solubilidade e tornando estes elementos mais presentes no solo.

As concentrações de Zinco nas três diferentes topografias foram relativamente baixas, devido se encontrarem em formas pouco móveis em solos tropicais. A presença de maiores teores de Zn na área de Platô/Vertente é provavelmente devida a seu teor ligeiramente maior em sedimentos argilosos e bem menor em arenitos. ${ }^{23}$ Hugen et al. ${ }^{4}$ também encontrou menores concentrações médias deste elemento em solos derivados de sedimentos arenosos, com valores de $\mathrm{Zn}$ em torno de $8,7 \mathrm{mg} \mathrm{kg}^{-1}$.

Ressalta-se que as diferenças entre os teores naturais de metais pesados em solos são atribuídas, sobretudo, ao material de origem e a fatores pedogenéticos. Mesmo em condições rigorosas de intemperismo durante a pedogênese e a exemplo do que ocorre com solos tropicais, a rocha mãe ainda exerce influência no conteúdo de metais pesados no solo. Essa influência é representativa quando o solo tem rochas básicas como material formador, em particular as rochas máficas que, devido à origem do magma, são naturalmente ricas em metais. Rochas sedimentares e ígneas ácidas cristalinas apresentam concentrações bem menores de metais pesados. ${ }^{4}$ 
Tabela 4. Concentrações dos elementos metálicos encontrados no solo em três diferentes topografias em ambiente natural na Amazônia central e para distintos solos brasileiros

\begin{tabular}{|c|c|c|c|c|c|c|}
\hline & \multicolumn{6}{|c|}{ Elementos Totais $\left(\mathrm{mg} \mathrm{kg}^{-1}\right)$} \\
\hline & \multicolumn{3}{|c|}{ Este estudo } & \multicolumn{3}{|c|}{ Outros estudos } \\
\hline & $\mathrm{P} / \mathrm{V}$ & $\mathrm{C}$ & $\mathrm{B}$ & Campos et al. ${ }^{20 \mathrm{a}}$ & Biondi et al. ${ }^{21 \mathrm{~b}}$ & Hugen et al..$^{4 \mathrm{c}}$ \\
\hline B & 12,9 & & 54,7 & - & - & - \\
\hline Ba & 11,0 & 2,1 & 1,4 & - & - & - \\
\hline Co & 17,6 & 2,1 & 1,4 & - & 9,6 & - \\
\hline $\mathrm{Cr}$ & 109,4 & 192,6 & 284,1 & - & - & - \\
\hline $\mathrm{Cu}$ & 3,5 & 2,7 & 3,1 & 65,0 & 28,0 & 29,5 \\
\hline $\mathbf{F e}$ & 20372,5 & 4137,3 & 2289,4 & - & 27685,0 & - \\
\hline Mn & 88,2 & 29,1 & 29,4 & - & 486,4 & - \\
\hline Mo & 1,6 & 12,6 & 16,8 & - & - & - \\
\hline $\mathbf{N i}$ & 3,5 & 7,2 & 9,3 & 18,0 & 62,4 & - \\
\hline Si & 2243,9 & 242,4 & 144,1 & - & - & - \\
\hline $\mathrm{Sr}$ & 13,7 & 2,1 & 0,8 & - & - & - \\
\hline $\mathbf{T i}$ & 11504,3 & 1351,2 & 713,4 & - & - & - \\
\hline V & 72,5 & 11,7 & 3,4 & - & - & - \\
\hline $\mathbf{Z n}$ & 8,2 & 2,7 & 3,6 & 39,0 & 67,9 & 28,5 \\
\hline
\end{tabular}

Legenda: $\mathrm{P} / \mathrm{V}=$ Platô/Vertente; $\mathrm{C}=$ Campinarana; $\mathrm{B}=$ Baixio. ${ }^{\mathrm{a}} 19$ latossolos no Brasil; ${ }^{\mathrm{b}}$ solos de referência de Pernambuco; ${ }^{\mathrm{c}}$ solos de diferentes litologias em Santa Catarina.

Na Tabela 4 estão apresentados os resultados das concentrações médias dos elementos metálicos determinadas nas amostras de solos coletados na Reserva Biológica do Cuieiras, no estado do Amazonas. Estes valores convêm à níveis de comparações para ambientes naturais na Amazônia.

Verifica-se a existência de uma grande variação dos teores de metais nos solos do estado do Amazonas que acompanha a diversidade de solos e rochas encontrados na região Amazônica. ${ }^{10}$ Considerando que o Brasil encontra-se em região de baixa latitude, apresenta grande extensão territorial e diversidade de regiões fisiográficas, que refletem as mais variadas classes de solos, a abordagem do tema, nestas condições, deve ser mais abrangente e ao mesmo tempo mais detalhada, respeitando as características e as condições ambientais em que cada solo se encontra.

Neste sentido e considerando a variabilidade de concentrações e teores naturais de metais em solos, Biondi et al. ${ }^{21}$ reforçam a necessidade de estudos regionalizados para determinação desses elementos. Assim também, as condições de formação podem apresentar peculiaridades locais, essas variações podem ser atribuídas às propriedades químicas e físicas, não apenas da classe, mas de cada perfil do solo.

Portanto, a variação observada nos Valores de Referência de Qualidade (VRQs) estabelecidos nos solos da Amazônia central deste trabalho, em relação aos determinados nas diversas regiões do Brasil, reflete a diversidade dos materiais de origem, fatores e processos de formação dos solos, bem como as características intrínsecas de cada classe de solo e metal analisado. ${ }^{24}$ Esses resultados corroboram a ampla variação de VRQs, e permitem observar que as determinações dos elementos metálicos realizadas neste estudo não devem ser comparadas aos Valores de Referência de Qualidade pela Resolução CONAMA 420/09.21 devido a não serem, estes últimos, valores determinados especificamente para o Estado do Amazonas, e sim para cada Estado da Federação, para fins de monitoramento dos impactos ambientais, em razão da enorme extensão territorial e diversidade geológica, geomorfológica e pedológica do país.

\section{CONCLUSÕES}

O Al trocável apresentou alta concentração nos solos com maior teor de argila (Platô/Vertente). Em contrapartida, o Na mostrou baixo potencial de disponibilidade nos solos estudados, certamente pela sua baixa abundância natural.

De maneira geral, solos nos ambientes de Platô/Vertente apresentaram maior potencial de disponibilidade da maioria dos metais pesados, exceto para $\mathrm{B}, \mathrm{Cr}, \mathrm{Mo}$ e Ni, estes sendo encontrados em maior concentração no ambiente de Baixio.

A análise química permitiu observar que as diferentes características das áreas influenciam na distribuição espacial dos elementos metálicos.

Este trabalho possibilitou a avaliação dos teores naturais de metais em três ambientes distintos (platô/vertente, campinarana e baixio). A partir desses resultados, têm-se uma referência do conteúdo de metais encontrados nessas três topografias, o que contribui para análise das características de solos locais, podendo servir como parâmetro e subsídio para estudos em ambientes de florestas naturais tropicais.

\section{REFERÊNCIAS}

1. Oliveira, R. C. B.; Martins, R. V.; Rev. Virtual Quim. 2011, 3, 88.

2. Salomons, W.; Förstner, U.; Metals in The Hydrocycle, $1^{\text {st }}$ ed.; Springer Verlag: Berlin, 1984.

3. Biondi, C. M.; do Nascimento, C. W. A.; Fabricio Neta, A. B.; Rev. Bras. Cienc. Solo 2011, 35, 1819.

4. Hugen, C.; Miquelluti, D. J.; Campos, M. L.; Almeida, J. A.; Ferreira, E. R. N. C.; Pozzan, M.; Revista Brasileira de Engenharia Agrícola e Ambiental 2013, 17, 622 .

5. Preston, W.; Nascimento, C. W. A.; Biondi, C. M.; Junior, V. S. S.; Silva, W. R.; Ferreira, H. A.; Rev. Bras. Cienc. Solo 2014, 38, 1028.

6. Higuchi, N.; Chambers, J.; Santos, J.; Ribeiro, R. J.; Pinto, A. C. M.; Silva, R. P.; Rocha, R. M.; Tribuzy, E. S.; Floresta 2004, 34, 295. 
7. Marques, J. D. O.; Luizão, F. J.; Geraldes, W. T.; Ferreira, S. J. F.; Rev. Bras. Cienc. Solo 2012, 36, 611.

8. Tomasella, J.; Hodnett, M.; Cuartas, L.; Nobre, A.; Waterloo, M.; Oliveira, S.; Hydrol. Processes 2008, 22, 2133.

9. Barroco Neta, E. F. B.; Nishiwaki, E.; Brazilian Applied Science Review 2018, 2, 1747 .

10. Quesada, C. A.; Lloyd, L.; Schwarz, M.; Patiño, S.; Baker, T. R.; Czimczik, C.; Fyllas, N. M.; Martinelli, L.; Nardoto, G. B.; Schmerler, J. S.; Santos, A. J. B.; Hodnett, M. G.; Herrera, R.; Luizão, F. J.; Arneth, A.; Lloyd, G.; Dezzeo, N.; Hilke, I.; Kuhlmann, I.; Raessler, M.; Brand, W. A.; Geilmann, H.; Moraes Filho, J. O.; Carvalho, F. P.; Araujo Filho, R. N.; Chaves, J. E.; Cruz Junior, O. F.; Pimentel, T. P.; Paiva, R.; Biogeosciences 2010, 7, 1515.

11. Pleysier, J. L.; Juo, A. S. R.; Soil Sci. 1980, 129, 205.

12. Linden, R.; Revista de Sistemas de Informação da FSMA 2009, 4, 18.

13. Ronquim, C. C.; Conceitos de fertilidade do solo e manejo adequado para as regiões tropicais, $1^{\mathrm{a}}$ ed.; Embrapa Monitoramento por Satélite: Campinas, 2010

14. Campos, M.; Santos, L.; Silva, D.; Mantovanelli, B.; Soares, M.; Revista agro@mbiente on-line 2012, 6, 102.

15. Miguel, P. S. B.; Gomes, F. T.; Rocha, W. S. D.; Martins, C. E.; Carvalho, C. A.; Oliveira, A. V.; CES Revista 2010, 24, 13.
16. Zaninetti, R. A.; Moreira, A.; Moraes, L. A. C.; Pesqui. Agropecu. Bras. 2016, 51, 1061.

17. Wu, L. F.; Shinzato, M. C.; Andrade, S.; Franchi, J. G.; Andrade, V. S.; Rev. Inst. Geogr. Geol. 2013, 34, 57.

18. Gheyi, H. R.; Dias, N. S.; Lacerda, C. F.; Gomes Filho, E.; Manejo da Salinidade na Agricultura: Estudos Básicos e Aplicados, $2^{\text {nd }}$ ed.; INCTSal: Fortaleza, 2016.

19. Pedrotti, A.; Chagas, R. M.; Ramos, V. C.; Prata, A. P. N.; Lucas, A. A. T.; Santos, P. B.; Revista Eletrônica em Gestão, Educação e Tecnologia Ambiental 2015, 19, 1308.

20. Campos, M. L.; Pierangeli, M. A. P.; Guilherme, L. R. G.; Marques, J. J.; Curi, N.; Commun. Soil Sci. Plant Anal. 2003, 34, 547.

21. Biondi, C. M.; do Nascimento, C. W. A.; Fabricio Neta, A. B.; Ribeiro, M. R.; Rev. Bras. Cienc. Solo 2011, 35, 1057.

22. Marques, J. J.; Schulze, D. G.; Curi, N.; Mertzman, S. A.; Geoderma 2004, 119, 179.

23. Raij, B. V.; Fertilidade do solo e manejo de nutrientes, $1^{\mathrm{a}}$ ed.; International Plant Nutrition Institute: Piracicaba, 2011.

24. Bini, C.; Sartori, G.; Wahsha, M.; Fontana, S.; J. Geochem. Explor. 2011, 109, 125. 